\title{
Adaptation of bacterial biotests for monitoring mycotoxins
}

\author{
Cs. Krifaton ${ }^{1}$, J. Kukolya ${ }^{3}$, S. Szoboszlay ${ }^{2}$, M. Cserháti ${ }^{2}$, \\ Á. Szücs ${ }^{1} \&$ B. Kriszt ${ }^{2}$ \\ ${ }^{I}$ Szent István University, Regional Center of Excellence, Hungary \\ ${ }^{2}$ Szent István University, \\ Environmental Protection and Environmental Safety, Hungary \\ ${ }^{3}$ Agruniver Holding Ltd., Hungary
}

\begin{abstract}
Mycotoxins are secondary fungal metabolites that have mutagenic, carcinogenic, teratogenic, immunomodulant and cytotoxic effects. Besides expensive chemical analytical methods, biotests can be alternative screening methods for selecting mycotoxin degrading microbes. Our aim was to monitor mycotoxins by bacterial biotests. Aflatoxin-B1 (AFB1), deoxynivalenol, zearalenon, T2-toxin and ochratoxin were analysed by two biotests: Aliivibrio fischeri luminescence assay and SOS-Chromotest using Escherichia coli. The A. fischeri bioluminescence assay is one of the most sensitive bacterial toxicity assays across a wide spectrum of toxicants; however, the effects of mycotoxins have been hardly examined. The inhibition effect of various mycotoxins on A. fischeri was determined in the range of $1-20 \mu \mathrm{g} / \mathrm{ml}$ toxin concentration. The test bacterium proved to be the most sensitive for AFB1. Less but pronounced inhibition of zearalenon was also determined, while other mycotoxins had no measurable toxic effect on A. fischeri. Based on these results we have adopted this method for monitoring microbial AFB1 biodegradation efficiency. The genotoxic effect of mycotoxins was analysed by SOS-Chromotest. The principle of the assay is the SOS response that is induced by DNA-damaging agents. We have examined AFB1 $0,078-10 \mu \mathrm{g} / \mathrm{ml}$ concentration. We found that the genotoxic effect of AFB1 is still detectable at $0,078 \mu \mathrm{g} / \mathrm{ml}$ concentration. SOS-Chromotest was successfully used to select microorganisms that have the best AFB1 degrading potential and can degrade AFB1 without genotoxic by-products. The applicability of SOS-Chromotest for screening mycotoxin degrader microbes
\end{abstract}


was confirmed by parallel ELISA and chemical analytical tests. We have adopted two bacterial biotests that are suitable for monitoring mycotoxin concentrations based on their biological effects. On the basis of these results a screening method was developed for microbes with AFB1 degrading potential. Furthermore, these methods can be appropriate tools for elucidating mycotoxin metabolism by high throughput screening of expression, and transposon mutagenesis clone libraries of the best AFB1 degrading strains.

Keywords: aflatoxin-B1, zearalenon, ochratoxin, T2-toxin, deoxynivalenol, SOSChromotest, genotoxicity, Alivibrio fischeri, screening, biodegradation.

\section{Introduction}

Mycotoxins are very complex micropollutants that can be found in every variety of grain and forage produced for food or feed. The most considered mycotoxins are aflatoxins (mainly B1) produced by Aspergillus spp., zearalenon, deoxynivalenol, T2-toxin and ochratoxin produced by Fusarium spp. These substances are secondary fungal metabolites that have mutagenic, carcinogenic, and teratogenic, immunomodulant and cytotoxic effects [1], thus biomonitoring of mycotoxins has an increasing importance nowadays. Besides expensive chemical analytical methods, biotests can be alternative screening methods for selecting mycotoxin degrading microbes as they provide prompt information, moreover they are reliable and cost effective methods [2]. Our aim was to monitor mycotoxins - aflatoxin B1 (AFB1), zearalenon (ZEA), deoxynivalenol (DON), T2-toxin (T2) and ochratoxin (OCHRA) - by bacterial biotests. A bioluminescence assay based on Aliivibrio fischeri marine bacterium is a widely used bacterial biotest for ecotoxicological testing in environmental industry. The test bacterium emits light in optimal conditions; this property is used to determine ecotoxicity in environmental biotechnologies [3-6]. The A. fischeri bioluminescence assay is one of the most sensitive bacterial cytotoxicity assays across a wide spectrum of toxicants [7-9]. The specific A. fischeri strain, NRRLB-11177, has been widely used for acute toxicity estimation and several commercial test kits, i.e., Microtox, LUMIStox and ToxAlert are based on this strain [10]. However, the effects of mycotoxins have been hardly examined. SOS-Chromotest, a simple bacterial colorimetric assay, was used in this study for testing genotoxicity. Scientific literature has reported the sensitivity of this test for AFB1 [11-13] and high correlation (60-100\%) with the widely used Ames test [12, 14-19]. Our aim was to develop bacterial biotests for monitoring mycotoxins and screening mycotoxin degrading microbes.

\section{Methods}

\subsection{SOS-Chromotest}

The test uses the PQ37 mutant strain of Escherichia coli wild type K12. The principle of the assay is that most genotoxins induce SOS response in the test bacteria. The test took advantage of an operon fusion placing lacZ, the structural 
gene for $\beta$-galactosidase, under the control of the sfiA gene, which is involved in cell division and make up - with another 17 genes - giving the SOS-error-prone. Thus $\beta$-galactosidase activity highly depends on sfiA expression [20]. We have carried out SOS-Chromotest according to Legault et al. [21]. SOS-Chromotest was originally designed as a test tube procedure to detect DNA damage [11]. This test makes it possible to use S9 rat liver homogenates to examine those compounds that have indirect genotoxic activity and need metabolic activation to actuate their genotoxic effect. The SOS-Chromotest Kit was purchased from Environmental Bio-Detection Products Inc., Canada. The test was conducted according to the manufacturer's instructions. We have tested AFB1, ZEA, OCHRA, T2 and DON. $10 \mu \mathrm{l}$ of AFB1 $(10 \mu \mathrm{g} / \mathrm{ml})$ in two fold serial dilution and $10 \mu \mathrm{l}$ of ZEA, DON, T2 and OCHRA in two concentrations $(10$ and $5 \mu \mathrm{g} / \mathrm{ml})$ were analysed. Enzyme activity ( $\beta$-galactosidase and alkaline-phosphatase relative concentrations) were measured by ELx800 (BioTek Instruments, Inc.) at 405 and $620 \mathrm{~nm}$. Induction factors (IF) indicative of genotoxicity were calculated by the following formula, eqn (1):

$$
I=\left(A_{405} n c \times A_{620} t\right) /\left(A_{405} t \times A_{620} n c\right)
$$

where nc is the negative control and $\mathrm{t}$ is the tested sample. An induction factor of 1,5 or more is determined as genotoxic [11].

\subsection{A. fischeri luminescence assay}

An acute bioluminescence assay was modified according to Sarter et al. [22]. The bioluminescent marine bacteria Aliivibrio fischeri (DSM-7151, NRRLB11177) was purchased from DSMZ. Cultures of the microorganism were stored on Bactomarine slant agar (Difco, USA) at $4^{\circ} \mathrm{C}$. Bactomarine broth (Difco, USA) was inoculated with 24 hour colonies from Bactomarine slant agar. The experiment was carried out in liquid cultures and luminescence was determined by a Toxalert $100^{\mathrm{TM}}$ (Merck, Germany) luminometer (Merck KGaA, Germany) after $3.5,10,15,25 \mathrm{~h}$ of incubation $\left(25^{\circ} \mathrm{C}, 30 \mathrm{rpm}\right.$ in shaking thermostat) according to Froehner et al. [23] by the following formula:

$$
\text { Inhibition }(\%)=\left(\left(\mathrm{C}_{\mathrm{tx}}-\mathrm{S}_{\mathrm{tx}}\right) 100\right) / \mathrm{C}_{\mathrm{tx}}
$$

where $\mathrm{C}_{\mathrm{tx}}$ gives the arithmetic mean of the bioluminescence values of parallel controls after the examined hour $(\mathrm{x}=$ contact time in point $)$ and $\mathrm{S}_{\mathrm{tx}}$ represents the bioluminescence average value of parallel samples determined at contact time in point.

\subsubsection{Mycotoxin monitoring with $A$. fischeri}

Basic experiments to investigate the sensitivity of the test-organism for mycotoxins, such as AFB1, ZEA, T2, OCHRA, and DON, were performed in 20 $\mathrm{ml}$ cultures of $A$. fischeri, in which optical density was adjusted to 0,1 at $550 \mathrm{~nm}$ (corresponding to $10^{6} \mathrm{CFU} / \mathrm{ml}$ ). Mycotoxins were purchased from Fermentec Ltd. (Israel) and were dissolved in acetone. Controls without mycotoxins 
contained the culture plus acetone. Tests with controls, AFB1 $(20,10,5,2,1$ $\mu \mathrm{g} / \mathrm{ml}), \mathrm{ZEA}, \mathrm{T} 2, \mathrm{OCHRA}$ and DON $(20,15,10 \mu \mathrm{g} / \mathrm{ml})$ were conducted in triplicate.

\subsection{Biodegradation tests}

According to published results [24] actinomycete strains - especially $R$. erythropolis strain DSM14303 [25] - are the best aflatoxin degraders. Based on these findings ten rhodococcus strains belonging to four species (Rhodococcus erythropolis, $R$. ruber, $R$. globerulus and $R$. rhodochrous) were used for the biodegradation experiment. Rhodococci from the strain collection of Agruniver Holding Ltd. (R. erythropolis strains N11, OM72, ZMF231, $R$ ruber N361, $R$. globerulus $\mathrm{N} 58$ and $R$. rhodochrous $\mathrm{K} 402$ ) and reference strains from international collections ( $R$. erythropolis DSM 4306, NCIMB9784, IFO12538, $R$. rhodochrous CW25 and ATTC12674) were chosen. The Escherichia coli strain K12 was also used as a non mycotoxin degrader control microbe. Cultures were streaked on LB agar and were incubated at $28^{\circ} \mathrm{C}$ for 72 hours. After checking purity, cells were inoculated into $50 \mathrm{ml} \mathrm{LB}$ media and were incubated at $170 \mathrm{rpm}, 28^{\circ} \mathrm{C}$ for 72 hours. Absorbance of stock cultures were adjusted to $\mathrm{OD}=0,6$. For degradation experiments, a stock solution of AFB1 (1000 ppm in acetone) was used to supplement cultures to a final concentration of $2 \mathrm{ppm}$. Degradation experiments were carried out in $50 \mathrm{ml} \mathrm{LB}$ medium. A microbe free blank (50 ml LB with 2ppm AFB1) and a negative control - inoculated with a non mycotoxin degrader E. coli K12 strain - were set in the experiment as well. Samples were taken from degradation systems in every 24 hours. These samples were centrifuged at $4600 \mathrm{rpm}, 4^{\circ} \mathrm{C}, 20 \mathrm{~min}$. The supernatant and pellet were separated, and stored at $-20^{\circ} \mathrm{C}$ until examination. The supernatant and pellet were analysed by High Performance Liquid Chromatography (Wessling Hungary Ltd., Hungary) and by an ELISA test (Soft Flow Ltd., Hungary). We also examined the supernatant of degradation systems by SOS-Chromotest.

\subsubsection{Enzyme linked immunosorbent assay (ELISA-tests)}

Toxin concentrations were determined by ELISA kits by the use of the TOXIWATCH system, SoftFow Biotechnology Ltd, Hungary. Measurements were carried out according to the manufacturer's instructions. In Toxiwatch ELISA Kits methanol $(9,4 \%)$ is used for toxin extraction, thus standard lines contain methanol as well. As the matrix of the bacterial supernatant was a LB medium that does not contain methanol, in the case of AFB1 standard points without methanol had to be used. Measurements were carried out in triplicate.

\subsubsection{High performance liquid chromatography (HPLC)}

Chemical analytical tests were made by Wessling Hungary Ltd. Toxin concentrations were determined by the standard ethanol method. After cleaning up immunoaffinity columns and derivatization, liquid chromatography for separation and fluorescence detection was used according to AOAC Official Method 990.33. Measurements were carried out with Agilent 1100 HPLC-FLD. The column was Supelco and the temperature of the column thermostat was 
$25^{\circ} \mathrm{C}$. Detection wavelengths regarding AFB1 were $365 \mathrm{~nm}$ (extinction) and 450 $\mathrm{nm}$ (emission). Injection happened with 100, 50, $10 \mu \mathrm{l}$ and the eluents were water $(68 \%)$, acetonitrile $(50 \%)$, isocratic.

\subsubsection{Application of SOS-Chromotest for analysing AFB1 biodegradation}

We have carried out the SOS-Chromotest as described above, except we have tested the supernatant of negative control in the biodegradation test - bacteria $(E$. coli) without mycotoxin degrading ability - here as a positive genotoxic control. $10 \mu \mathrm{l}$ of supernatant originated from degradation systems, a sample of controls and blank were added to corresponding wells and tested by SOS-Chromotest. We have compared the results of the SOS-Chromotest with parallel ELISA and chemical analytical tests.

\subsubsection{Application of $A$. fischeri luminescence assay for analysing AFB1 biodegradation}

We have classified microbes into three groups: microbes that have the highest, medium and insufficient AFB1 degradation potential. In that case we have set AFB1degradation systems with 4 ppm AFB1 in three parallels, where microbes were cultured in half strength (half amount of salts) Bactomarine broth. Moreover, we set negative controls without AFB1 contamination for clarifying whether the metabolic by-products of these microbes have a toxic affect on $A$. fischeri. In every 24 hours we took $8-8-8 \mathrm{ml}$ samples from parallel systems and centrifuged them as described above. The supernatant was decanted and filtered through $0,45 \mu \mathrm{m}$ membrane, then $10 \mathrm{ml}$ of samples were distributed in $100 \mathrm{ml}$ Erlenmayer flaks. We recovered salts in samples corresponding to the original Bactomarine broth, vortexed them, then filled them up with liquid culture of $A$. fischeri, in which the optical density was adjusted to 0,2 at $550 \mathrm{~nm}$. Luminescence at $\mathrm{t}_{0}$ was checked, then the samples were incubated at $25^{\circ} \mathrm{C}, 30$ rpm in a shaking thermostat, and toxicity was determined as described above.

\section{Results and discussion}

\subsection{Biomonitoring of mycotoxins with SOS-Chromotest}

We have analysed AFB1 $(10-0,078 \mu \mathrm{g} / \mathrm{ml})$ in two fold serial dilution, and ZEA, OCHRA, T2 and DON in two concentration ranges (10 and $5 \mu \mathrm{g} / \mathrm{ml})$. On the basis of our results, the SOS-Chromotest proved to be a less effective tool for screening the biological effects of ZEA, OCHRA, T2 and DON. In the case of these toxins the difference of genotoxic activity between native and activated mycotoxins were not significant; IF was $1,7 \pm 0,2$ at $10 \mu \mathrm{g} / \mathrm{ml}$ and $1,5 \pm 0,2$ at 5 $\mu \mathrm{g} / \mathrm{ml}$. In the case of AFB1 we found that as low as $0,078 \mu \mathrm{g} / \mathrm{ml}$ concentration of metabolically activated AFB1 induced the SOS repair system of the test bacterium and indicated a highly genotoxic 2,0 IF number (Fig 2.). These findings fit well with the published SOS-Chromotest results and underline the danger of AFB1 - the most potent carcinogenic natural substance. A detectable level of AFB1 approaches limits set in food and feed safety, thus the SOS- 


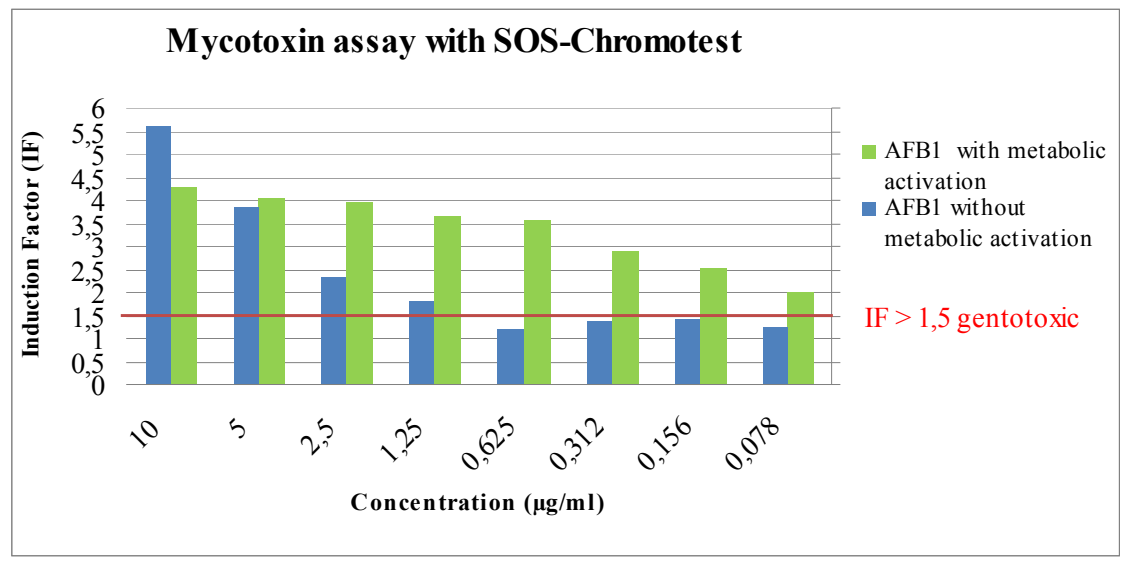

Figure 1: $\quad$ Genotoxicity of AFB1 measured by SOS-Chromotest.

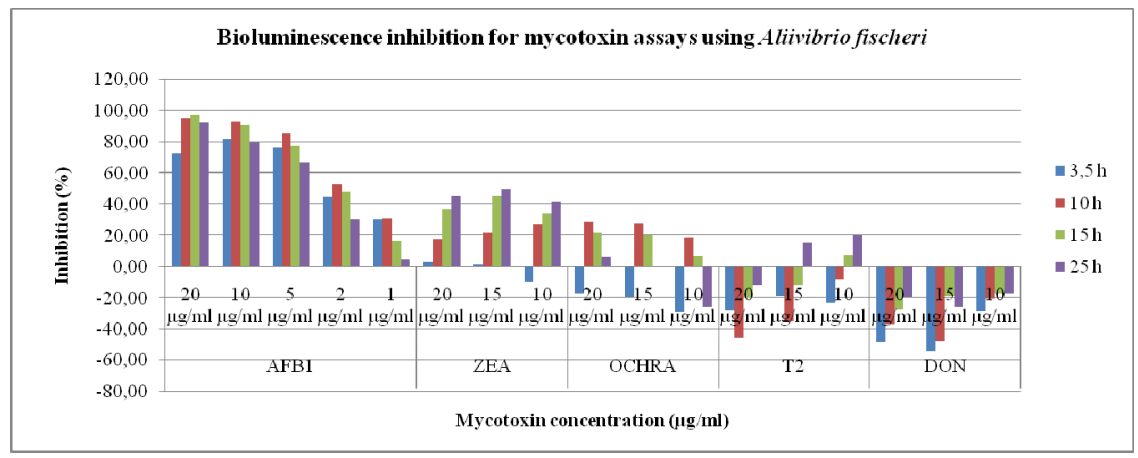

Figure 2: $\quad$ Bioluminescence inhibition for mycotoxins using A. fischeri.

Chromotest can be an appropriate tool for direct monitoring of AFB1 contaminated samples.

\subsection{Biomonitoring of mycotoxins with $A$. fischeri}

Our aim was to examine AFB1, ZEA, OCHRA, T2 and DON and to provide information about their toxicity with the help of an $A$. fischeri luminescence bioassay. Up to now only one publication dealt with this method oriented to mycotoxins [22], where AFB1 $(10 \mu \mathrm{g} / \mathrm{ml})$ and DON $(20 \mu \mathrm{g} / \mathrm{ml})$ were tested. We have tested three more toxins and all were used in a much wider concentration range. The $A$. fischeri luminescence assay showed great sensitivity in the case of AFB1, yet $1 \mu \mathrm{g} / \mathrm{ml}$ concentration of AFB1 was detectable. On the basis of our results, beside AFB1, ZEA has inhibited luminescence by $50 \%$ at $15 \mu \mathrm{g} / \mathrm{ml}$ range. Regarding DON, we measured similar luminescent gain in the manner of Sarter et al. [22]. However, adequate response in the case of T2 and OCHRA 
could not be measured. The results are shown in Fig. 2. According to our measurements this method is not suitable for direct monitoring, even of AFB1 contamination of food and feed stuffs, as it works at a much higher concentration than the current limits.

\subsection{Application of SOS-Chromotest for analysing AFB1 biodegradation}

We set AFB1 degradation tests to find microbes that have outstanding AFB1 degradation potential. We analysed the AFB1 degradation ability of 11 microbes on AFB1 (2 ppm) contaminated samples (Table 1). Our assumption was that the genotoxicity of samples ceased when microbes degraded AFB1 without forming a genotoxic by-product. The genotoxicity of the examined samples is expressed in Induction factors (IF). Out of 11 microbes we have selected six strains that successfully degraded AFB1 in 72 hours. Moreover, we have determined four strains that could eliminate genotoxic contamination in 48 hours. Our results and those made by ELISA-tests and by HPLC were highly correlated. In most cases genotoxicity ceased when ELISA-tests and HPLC indicated the decrease of AFB1 concentration. Interestingly, IFO 12538 showed genotoxicity, while great toxin elimination was detected $(>90 \%)$ by ELISA and HPLC tests. In the case of this strain appearance, genotoxic by-products are assumable, which underlines the necessity of such biomonitoring measurements. Coherence between degradation ability and genotoxicity are in clear relief in the case of strains that have inefficient AFB1 degradation potential (N361, N58), which IF approximates the genotoxicity of negative control sample injected with $E$. coli. Furthermore, it indicates that different rhodococcus strains may use different routes for AFB1 degradation.

Table 1: $\quad$ Results of AFB1 (2ppm) biodegradation tests.

\begin{tabular}{|c|c|c|c|c|c|c|}
\hline \multirow{3}{*}{ Microbe } & \multirow{3}{*}{ Strain } & \multicolumn{3}{|c|}{ SOS-Chromotest } & ELISA-system & Chemical analysis \\
\hline & & \multicolumn{3}{|c|}{ Induction Factor } & Degradation (\%) & Degradation (\%) \\
\hline & & $24 \mathrm{~h}$ & $48 \mathrm{~h}$ & $72 \mathrm{~h}$ & $72 \mathrm{~h}$ & $72 \mathrm{~h}$ \\
\hline E. coli & $\mathrm{C}$ & 2.42 & 2.13 & 2.32 & $<20$ & $<20$ \\
\hline \multirow{6}{*}{ R. erythropolis } & N11 & 1.98 & 1.36 & 1.3 & 97.64 & 81.71 \\
\hline & DSM4306 & 2.13 & 1.32 & 1.2 & 97.56 & 99.98 \\
\hline & NCIMB9784 & 2.09 & 1.82 & 1.2 & 97.11 & 98.55 \\
\hline & IFO12538 & - & - & 1.6 & 96.40 & 94.52 \\
\hline & OM72 & 3.09 & 2.1 & 1.68 & 79.20 & 84.30 \\
\hline & ZFM231 & - & - & 1.84 & 72.87 & 71.69 \\
\hline R. ruber & N361 & - & - & 3.0 & $<20$ & $<20$ \\
\hline R. globerulus & N58 & - & - & 2.6 & 20.79 & $<20$ \\
\hline \multirow{3}{*}{ R. rhodochrous } & CW25 & 1.83 & 1.26 & 1.2 & 97.97 & 99.98 \\
\hline & ATTC12674 & 2.3 & 1.4 & 1.2 & 97.90 & 96.05 \\
\hline & K402 & - & 1.92 & 1.38 & 98.11 & 99.92 \\
\hline
\end{tabular}




\subsection{Application of $A$. fischeri luminescence assay for analysing AFB1 biodegradation}

Strains were classified in three groups on the basis of ELISA-tests and chemical analysis: outstanding (80-100\%), good (70-80\%) and insufficient AFB1 degrading strains. We analysed these strains by an A. fischeri luminescence inhibition test for the remaining toxicity of their AFB1 biodegradation. The results of the inhibition test are illustrated in Figure 3. High luminescence inhibition was found in the case of "insufficient" rhodococcus strains (N58, N361). "Good" strains (ZFM231, OM72) showed less inhibition than insufficient strains, but caused greater inhibition than excellent strains. Those strains that have the greatest, more than $99 \%$, degradation potential did not cause inhibition for the third day of the biodegradation process, rather increased luminescence. Interestingly, in the $A$. fischeri luminescence assay, HPLC and ELISA-tests showed great degradation ability for $R$. erythropolis IFO11453, but at the same time the SOS-Chromotest showed genotoxicity. In the case of ATTC12674 slight cytotoxic effect was demonstrable after great toxin degradation. This underlines the necessity of using different bacterial biotests, since these tests measure different biological effects: genotoxicity and cytotoxicity.

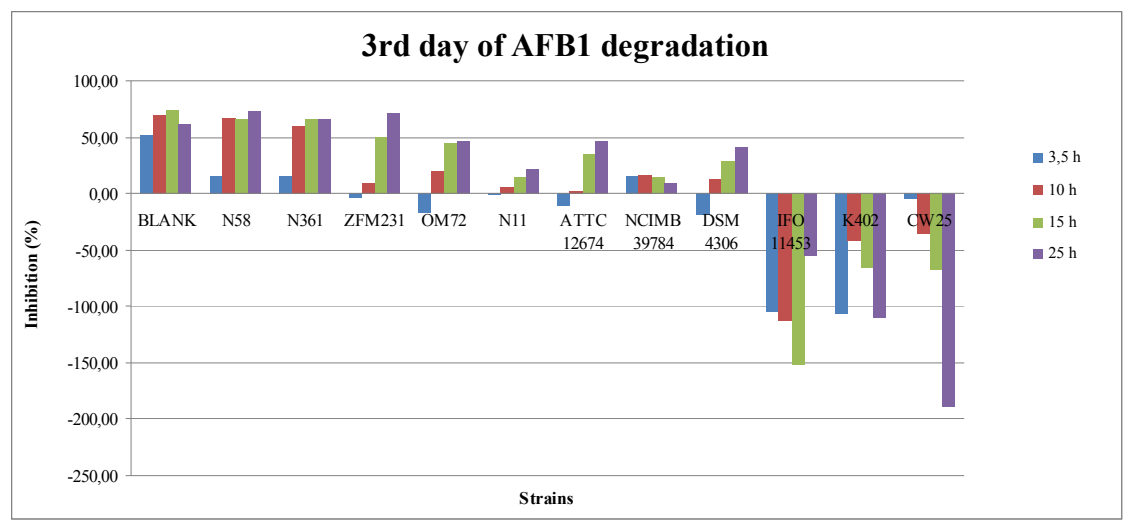

Figure 3: Luminescence inhibition by AFB1 biodegradation derivatives on $A$. fischeri.

\section{Conclusion}

We have adopted two bacterial biotests, $A$. fischeri luminescence assay and SOSChromotest, for monitoring AFB1, ZEA, OCHRA, T2 and DON contamination. The toxin levels of ZEA, DON, OCHRA and T2 needed for an SOS-system or an $A$. fischeri assay were two or three order of magnitude higher than current mycotoxin limits - so direct application of these tests is not possible. However, SOS-Chromotests would be a suitable tool for AFB1 monitoring, since the detectable limit of AFB1 by this test is around the regulated maximum levels of 
AFB1 contamination in food and feedstuffs. Nevertheless, both methods seem to be suitable for screening mycotoxin degrading microbes. The SOS-Chromotest is suitable for monitoring biodegradation purposes of AFB1, as the test is appropriate for detecting the most dangerous biological effect of aflatoxin. $A$. fischeri luminescence assay is also suitable for screening AFB1 degrading microbes, since the $A$. fischeri test showed slighter toxicity in the case of strains with the best degradation ability in correllation with the paralell analitical and ELISA methods. In particular, the simultaneous application of both biotests was useful, as it cleared up any possible remaining mutagen effect even in the case of microbes with excellent degradation potential. Moreover, in the A. fischeri system a remaining cytotoxic effect was demonstrable after great toxin degradation and ceased genotoxicity. Thus, the combination of the above mentioned tests are crutial for the selection of safe and active microbial strains for further biodetoxification technologies. To sum up, the A. fischeri luminescence assay and SOS-Chromotest are definitely applicable for screening microbial strain collections, thousands of genetically improved microbe clones or transposon mutagenesis libraries for AFB1 degradation activity, as these are reliable, relatively simple, cheap and rapid methods.

\section{Acknowledgement}

This study was supported by the NKTH TECH_08-A3/2-2008-0385 (OM00234/2008) MYCOSTOP grant.

\section{References}

[1] Enomoto, M., Saito, M., 1972. Carcinogens produced by fungi. Annual Review of Microbiology 26: 279-312.

[2] Sarter, S., Zakhia, N., 2004. Chemiluminescent and bioluminescent assays as innovative prospects for mycotoxin determination in food and feed. Luminescence 19: 345-351.

[3] Fernandez-Alba, A.R., Guil, M.D.H., Lopez, G.D., Chisti, Y., 2002. Comparative evaluation of the effects of pesticides in acute toxicity luminescence bioassays. Analytica Chimica Acta 451: 195-202.

[4] Peinado, M.T., Mariscal, A., Carnero-Varo, M. Fernandez-Crehuet, J., 2002. Correlation of two bioluminescence and one fluorogenic bioassay for the detection of toxic chemicals. Ecotoxicology and Environmental Safety 53: $170-177$.

[5] Repetto, G., Jos, A., Hazen, M.J., Molero, M.L., Del Peso, A., Salguero, M., Del Castillo, P., Rodriguez-Vicente, M.C. and Repetto, M., 2001. A test battery for ecotoxicological evaluation of pentachlorophenol. Toxicology in Vitro 15: 503-509.

[6] Ribo, J.M., Kaiser, K.L.E., 1983. Effects of selected chemicals to photoluminescent bacteria and their correlation with acute and sublethal effects on other organisms. Chemosphere 12: 1421-1442. 
[7] Kaiser, K. L. E., 1998. Correlation of Vibrio fischeri Bacteria Test with Bioassay Data for Other Organisms. Environmental Health Perspectives 106: 583-591

[8] Steinberg, S.M., Poziomek, E.J., Engelmann, W.H., Rogers, K.R., 1995. A review of environmental applications of bioluminescence measurements. Chemosphere 30(11): 2155-2197

[9] Cronin, M.T.D., 1999. Microtox as a Substitute for Acute Fish Toxicity Testing. TestSmart - A Humane and Efficient Approach to SIDS Data Workshop of the Johns Hopkins Center for Alternatives to Animal Testing, April 26-27 Fair Lakes, Fairfax

[10] Farre M, Barcelo D., 2003. Toxicity testing of wastewater and sewage sludge by biosensors, bioassays and chemical analysis. Trends Anal Chem; 22(5): 299-310.

[11] Quillardet, P., Hofnung, M., 1985. The SOS Chromotest, a colorimetric bacterial assay for genotoxins: procedures. Mutation Research 147(3):65-78

[12] Quillardet, P., de Bellecombe, C., Hofnung, M., 1985. The SOS Chromotest, a colorimetric bacterial assay for genotoxins: validation study with 83 compounds. Mutation Research 147(3): 79-95.

[13] Auffray, Y., Boutibonnes, P., 1984.Genotoxic activity of some mycotoxins using the sos chromotest. Mycopathologia 100: 49-53.

[14] Mamber, S. W., W. G. Okasinski, C. D. Pinter, and J. B. Tunac. 1986. The Escherichia coli K-12 SOS Chromotest agar spot test for simple, rapid detection of genotoxic agents. Mutat. Res. 171:83-90.

[15] Brams A, Buchet JP, Crutzen-Fayt MC, De Meester C, Lauwerys R, Léonard, A., 1987. A comparative study, with 40 chemicals, of the efficiency of the Salmonella assay and the SOS chromotest (kit procedure). Toxicol Lett. 38: 123-133

[16] von der Hude W, Behm C, Gürtler R, Basler A., 1988. Evaluation of the SOS chromotest. Mutat Res. 203(2):81-94

[17] Eder E; Deininger C; Kütt W, 1989. Genotoxicity of monofunctional methanesulphonates in the SOS chromotest as a function of alkylation mechanisms. A comparison with the mutagenicity in S. typhimurium TA100. Mutation research 211: 51-64

[18] McDaniels, A. E., Reyers, A. L., Wymer, L. J., Rankin, C. C., and Stelma, G. N., 1990. Comparison of the Salmonella (Ames) test, umu test, and the SOS chromotest for detecting genotoxins. Environ. Mol. Mutagen. 16: 204215.

[19] $\mathrm{Xu}, \mathrm{H} . \mathrm{H}$. and Schurr, K.M. (1990) Genotoxicity of 22 pesticides in microtitration SOS chromotest, Toxicity Assess., 5: 1-14

[20] Quillardet, P., Huisman, O., D’ari, R., Hofnung, M., 1982. SOS chromotest, a direct assay of induction of an SOS function in Escherichia coli K-12 to measure genotoxicity. Proc. Natl. Acad. Sci. USA Genetics 79: 5971-5975.

[21] Legault, R., Blaise, C., Rokosh, D., Chong-Kit, R., 1994. Comparative assessment of the SOS Chromotest kit and the Mutatox test with the Salmonella plate incorporation (Ames test) and fluctuation tests for 
screening genotoxic agents. Environmental Toxicology and Water Quality 9: 45-57.

[22] Sarter, S., Metayer, I., Zakhia, N., 2008. Effects of mycotoxins, aflatoxin B1 and deoxynivalenol, on the bioluminescence of Vibrio fischeri. World Mycotoxin Journal 1(2): 189-193.

[23] Froehner, K., Meyer, W., Grimme, L.H., 2002. Time-dependent toxicity in the long-term inhibition assay with Vibrio fischeri. Chemosphere 46: 987997.

[24] Teniola, O.D., Addo, P.A., Brost, I.M., Färber, P., Jany, K.-D., Alberts, J.F., Van Zyl, W.H., Steyn, P.S., Holzapfel, W.H., 2005. Degradation of aflatoxin B1 by cell-free extracts of Rhodococcus erythropolis and Mycobacterium fluoranthenivorans sp. nov. Int. J. Food Microbiol. 105: 111-117.

[25] Alberts, J.F., Engelbrecht, Y., Steyn, P. S., Holzapfel, W.H. and van Zyl W., H. (2006): Biological degradation of aflatoxin B1 by Rhodococcus erythropolis cultures. International Journal of Food Microbiology 109, $121-126$ 